\title{
Literatura Infantil: Caminhos Para Compreender O Mundo
}

\section{Chillren's Literature: Ways to Understand the World}

DOI: $10.54019 /$ sesv3n1-010

Recebimento dos originais: 05/07/2021

Aceitação para publicação: 20/08/2021

\section{Poliana Bruno Zuin}

Doutora e Professora do Ensino Básico, Técnico e Tecnológico (EBTT) da Unidade de Atendimento à Criança (UAC) e do Programa de Pós-Graduação em Linguística (PPGL-UFSCar) da Universidade Federal de São Carlos - UFSCar. E-mail: polianazuin@gmail.com

\section{Luís Fernando Soares Zuin}

Doutor e Professor na Faculdade de Zootecnia, Engenharia de Biossistemas e Engenharia de Alimentos (FZEA-USP) e do Programa de Pós-Graduação em Ciências, Tecnologia e Sociedade (PPGCTs-UFSCar) da Universidade Federal de São Carlos - UFSCar.

\section{Amarilio Ferreira Junior}

Doutor e Professor do Departamento de Educação (DED-UFSCar) e do Programa de Pós-Graduação em Educação (PPGE-UFSCar) da Universidade Federal de São Carlos e Professor Pesquisador do CNPQ.

\section{Amanda Dourado Souaza Akahosi Fernandes}

Doutora e Professora do Departamento de Terapia Ocupacional (DTO-UFSCar) da Universidade Federal de São Carlos - UFSCar.

\section{Sandra Regina Buttros Gattolin}

Doutora e Professora do Departamento de Letras (DL-UFSCar) e do PPGL (UFSCar).

\section{Alessandra Del Re}

Doutora de Professora do Departamento de Linguística da Faculdade de Ciências e Letras (UNESP-Araraquara)

\section{Monalisa Muniz}

Doutora e Professora do Departamento de Psicologia da Universidade Federal de São Carlos - UFSCar.

\section{Isadora Pascoalino Mariotto}

Graduanda em Pedagogia. Universidade Federal de São Carlos - UFSCar.

\section{Raquel Franco Tassoni}

Graduanda em Pedagogia. Universidade Federal de São Carlos - UFSCar. 
O programa de extensão "Linguagens na Educação Infantil (Ledif- ProExUFSCar)" compreende diferentes projetos de extensão e envolve professores, estudantes de graduação e pós-graduação de diferentes áreas, tais como: Pedagogia, Letras, Linguística, Educação Especial, Psicologia, Terapia Ocupacional, Educação Física e Tradução e Interpretação em Libras. Esse programa ocorre paralelamente ao trabalho desenvolvido na Unidade de Atendimento à Criança (UAC) da UFSCar e tem como objetivo inserir os alunos de graduação nas situações práticas do cotidiano da sala de aula, utilizando a Literatura Infantil como mediadora da prática docente e dos trabalhos com os diferentes gêneros discursivos por meio de rodas de leitura e de conversa, sendo a literatura eixo para os diálogos problematizadores. Em decorrência da pandemia, foram realizadas algumas adequações para o ensino remoto, usandose das tecnologias informacionais e comunicacionais (TICs) como instrumentos mediadores dessas práticas. Dentre os objetivos visados com o projeto, destacamos: ampliar a linguagem oral e escrita, contribuir com a expressão e linguagem corporal, incentivar o desenvolvimento da linguagem plástica e da coordenação motora, possibilitar o entendimento dos sentimentos, estimular a autonomia e as relações sociais. O referencial teórico e metodológico são os pressupostos da teoria Histórico-Cultural, os estudos da Filosofia da Linguagem de Bakhtin e conceitos de Paulo Freire. Concluímos que as práticas de mediação relacionadas à literatura infantil, realizada em parceria com as famílias no contexto de pandemia, proporcionou às crianças descobrir o mundo via diferentes formas de linguagens e gêneros textuais, permitindo a interação com os outros e com o mundo.

Palavras-chave: Educação Infantil; Literatura Infantil; Letramento; Práticas de Ensino; Processos de Ensino e Aprendizagem.

\section{ABSTRACT}

The extension program "Languages in Early Childhood Education (Ledif-ProExUFSCar)" comprises different extension projects and aims to involve teachers, undergraduate and graduate students from different areas, such as: Pedagogy, Languages, Linguistics, Special Education, Psychology, Occupational Therapy, Physical Education and Translation and Interpretation in Libras. The development of these projects occurs together with the work developed within the groups $(2,3$ and 4), whose professor and coordinator of the Program and Projects (Prof. Poliana Bruno Zuin) develops them in their classrooms at the Child Care Unit ( UAC) of UFSCar. This program aims to insert undergraduate students in everyday practical situations, using Children's Literature as a mediator of teaching practice and work with different discursive genres through reading and conversation circles, with literature being the axis for problematizing dialogues. As a result of the pandemic, some adjustments were made to remote learning, using informational and communicational technologies (ICTs) as mediating instruments for these practices. Among the aims of the project, we highlight: expand oral and written language, contribute to expression and body language, encourage the development of plastic language and motor coordination, enable the understanding of feelings, encourage autonomy and social relationships. The theoretical and methodological framework are the assumptions of Historical- 
Cultural theory, the studies of Bakhtin's Philosophy of Language and Paulo Freire's concepts. We conclude that the mediation practices related to children's literature, carried out by us in partnership with families in the context of the pandemic, allowed children to discover the world via different forms of textual languages and genres, allowing the acquisition of writing as a social practice of interaction with with others and with the world.

Keywords: Early Childhood Education; Children's literature; Literacy; Teaching Practices; Teaching and Learning Processes.

\section{O CONTEXTO DO ENSINO REMOTO E AS PRÁTICAS DE ENSINO}

As práticas de ensino aqui relatadas ocorreram em uma sala de Educação Infantil localizada na Unidade de Atendimento à Criança (UAC) na Universidade Federal de São Carlos-UFSCar, cujos autores estão de algum modo relacionados a essas práticas como colaboradores, seja como orientadores, pesquisadores, estagiários, voluntários, etc. Estudar uma determinada realidade é relevante para os estudos de abordagem qualitativa, próprios da pesquisa-ação e pesquisas colaborativas.

De acordo com os estudos de Freitas (2000, p.26), a abordagem qualitativa de pesquisa, com o viés do materialismo-histórico, visa abordar os aspectos descritivos e as percepções pessoais de um contexto particular, pois este é valorizado como instância da totalidade social, de forma que procurando compreender os sujeitos envolvidos, busca-se compreender também o seu contexto. Lüdke e André (1986) evidenciavam que na educação ocorrem a ação de inúmeras variáveis agindo e interagindo ao mesmo tempo, por isso, torna-se necessário analisar tal particularidade dentro de um contexto social mais amplo. Conforme Vygotsky (1995), a valorização de condutas cotidianas possui um valor científico à medida que o pesquisador consegue analisar e interpretar tais fragmentos como parte de um todo que é histórico.

Devido à Pandemia ocasionada pela Covid-19, a UAC no dia 16 de março de 2020 teve suas portas fechadas, sendo necessário que os professores e sua equipe de trabalho pensassem em novas estratégias de interação e acolhimento às crianças e suas famílias. Partindo dos Projetos de Extensão e de Pesquisa que a coordenadora deste programa desenvolve em sua sala de aula com crianças dos grupos $(2,3 \text { e } 4)^{1}$ foi possível um replanejamento de estratégias para acolher as

\footnotetext{
${ }^{1}$ A UAC possui a seguinte estrutura: berçário (4 meses a 1 ano); Grupo 1 (1 ano a 2 anos);
} 
crianças e suas famílias da melhor forma possível.

Tendo a professora sete anos de experiência, sentiu a necessidade de realizar trabalhos em parceria não somente com os professores dos distintos departamentos e alunos, mas também buscou a parceria entre escola e família, tornando-se esse eixo uma de suas áreas de pesquisa. A identificação dessa necessidade, permitiu que a docente construísse antes mesmo da pandemia uma relação dialógica com os familiares, a fim de que esses pudessem se sentir seguros e, consequentemente, passar essa segurança aos seus pequenos. Desta maneira, um grupo de WhatsApp já havia se constituído para dialogar, conversar, enviar sugestões de leitura, bem como o semanário e fotografias das crianças no dia a dia da sala de aula. Com a pandemia o uso desse instrumento pré-existente se intensificou e surgiu como ferramenta de acolhimento às crianças e suas famílias, algumas vezes de forma coletiva, outras individualmente.

Em diálogo com os familiares foi proposto um trabalho a partir da Literatura Infantil, mas que envolvesse os diferentes campos de experiências trazidos pelo Documento da Base Nacional Curricular Comum BNCC (2017) que rege a Educação Infantil, primeira etapa da Educação Básica, sendo eles: o eu, o outro e o nós; corpo, gestos e movimento; traços, sons, cores e formas; escuta, fala, pensamento e imaginação; espaço, tempo, quantidades, relações e transformações. Pensando nesses diferentes campos de experiências podemos utilizar a "Literatura Infantil" como eixo mediador de uma prática multidisciplinar. Com a pandemia e o necessário ensino remoto, a literatura infantil e o uso do Whatssap, assim como de outras TICs se integraram a fim de que fosse possível o cumprimento dos objetivos propostos. Desta maneira, a literatura se constituiu como objeto integrador entre os diferentes campos, e também objeto de acolhimento e interação entre os professores com as crianças e suas famílias.

Apresenta-se ainda, como um portal para o conhecimento, para a imaginação, para desbravar diferentes culturas, personalidades, formas distintas de escritas, estilos de autores, enfim uma polifonia de vozes que nos encanta e nos convida a recontar e contar novas histórias. Com a literatura as crianças são convidadas a explorarem diferentes sensações e sentimentos, por meio dela podemos introduzir

Grupo 2 (2 anos a 3 anos); Grupo 3 (3 anos a 4); Grupo 4 (4 anos a 5) e Grupo 5 (5 anos e 11 meses). 
diferentes idiomas, podemos problematizar questões que fazem parte do nosso cotidiano, sendo um importante instrumento de conscientização, conhecimento e criatividade. Abramovich (1999, p.17) aponta que:

"(...) é ouvindo histórias que se pode sentir emoções importantes, como tristeza, raiva, irritação, bem-estar, medo, alegria e tantos outros mais, ao viver o que as narrativas provocam em quem as ouve...permite ouvir, sentir e enxergar com o imaginário".

Em tempos de isolamento social ocasionado pela Pandemia da Covid-19, vislumbramos a literatura como a principal protagonista das práticas de ensino remoto. Vídeos de contação de histórias tornaram-se o principal recurso de muitos professores pelo mundo afora. O uso das TICs por esses profissionais propiciou ainda, enquadramentos dos livros, efeitos, a voz própria do professor nos desenhos animados e histórias animadas pré-existentes, tal como podemos observar na plataforma Youtube. Nunca a tecnologia havia sido tão utilizada nos ambientes da Educação Infantil como nesses dois últimos anos.

A escolha à priori dos Contos de Fadas como objeto mediador do trabalho docente para as faixas etárias dos 3 a 5 anos se deu devido à necessidade que as crianças possuem em relação ao seu desenvolvimento ético e moral perante o seu meio social, momento em que se inicia também a sua atenção, a sua capacidade de colaboração e entendimento das regras sociais. Os Contos de Fadas com suas histórias universais também fizeram parte do imaginário da maioria dos adultos, o que permitiu a eles um conhecimento prévio da maior parte das histórias escolhidas para se trabalhar e aproximar o mundo fantasioso do mundo real. Nesse momento de pandemia as novas versões dos contos clássicos que trazem um final feliz também nos trouxeram a possibilidade de pensamentos positivos nas crianças nesse momento de isolamento social o qual abateu muitas delas. De acordo com Garcia (2019, p. 12):

Essa narrativa está arraigada nas visões de mundo e de relacionamento romântico de milhões de pessoas, nas camadas mais profundas do inconsciente coletivo, como elemento constitutivo da cultura ocidental e do pensamento coletivo. Os contos de fadas se transformam em obra literária com as compilações de Charles Perrault e os irmãos Grimm. 
Com essas prerrogativas foram elencados 18 contos de fadas trabalhados no decorrer do ano letivo de 2021, sendo: Cachinhos Dourados e os Três Ursos (conto inglês) João e o Pé-de-Feijão (conto inglês), Chapeuzinho Vermelho (conto francês), Os Três Porquinhos (conto australiano), O Lobo e os 7 Cabritinhos (conto alemão), A Galinha Ruiva (conto russo), Os três Bodes da Montanha (conto norueguês), João e Maria (conto alemão), A princesa e a ervilha (conto dinamarquês) Cinderella (origem italiana, mas escrita por Perrault), Branca de Neve (origem alemã, compilado pelos irmãos Grimm), O Mágico de Oz ( L. Frank Baum - narrativa americana), O Jardim Secreto (Frances Hodgson Burnett escritora inglesa), Alice no País das Maravilhas ( Lewis Carrol), A Pequena Sereia ( Hans Cristian Anderson- Dinamarca), O Patinho Feio ( Hans Cristian Anderson Dinamarca), A garota dos Fósforos (conto dinamarquês) e, por fim, o Boneco de Gengibre ( história popular escandinava).

Selecionados esses contos, foi feito um planejamento para que cada um tivesse a durabilidade de duas semanas, buscando-se trabalhar os diferentes projetos, sendo eles:

Quadro 1: Primeira Semana

\begin{tabular}{|l|l|l|l|l|l|}
\hline & Segunda & Terça & Quarta & Quinta & Sexta \\
\hline Projetos & $\begin{array}{l}\text { Leitura, Reconto } \\
\text { e } \\
\text { Representações }\end{array}$ & Libras & $\begin{array}{l}\text { Sentimentos } \\
\text { e Emoções }\end{array}$ & $\begin{array}{l}\text { Artes } \\
\text { Plásticas }\end{array}$ & $\begin{array}{l}\text { Eu e Meu } \\
\text { Mundo }\end{array}$ \\
\hline
\end{tabular}

Quadro 2: Segunda Semana

\begin{tabular}{|c|c|c|c|c|c|}
\hline & Segunda & Terça & Quarta & Quinta & Sexta \\
\hline Projetos & $\begin{array}{l}\text { Leitura } \\
\text { (uma nova } \\
\text { versão) }\end{array}$ & Inglês & $\begin{array}{l}\text { Corpo e } \\
\text { Movimento }\end{array}$ & $\begin{array}{l}\text { Artes } \\
\text { Plásticas }\end{array}$ & $\begin{array}{l}\text { Eu e Meu } \\
\text { Mundo } \\
\text { Lives } \\
\text { (google } \\
\text { meet) }\end{array}$ \\
\hline
\end{tabular}

Diante do exposto, os trabalhos foram sendo realizados pela equipe composta por professores, estagiários remunerados e curriculares, voluntários dos projetos de extensão, mestrandos, doutorandos e pesquisadores. Para que pudéssemos dialogar a respeito das propostas, uma reunião a cada quinze dias foi realizada a fim de que a professora da turma pudesse falar o que estava pensando (sua intencionalidade da ação docente) e para que pudesse em diálogo e parceria receber sugestões, novas perspectivas e formas de trabalho.

Assim, uma infinidade de atividades foi cotejada, cujos produtos foram em sua 
maioria: PDFs (realizados no Canva e também com objetivos da atividade para as diferentes áreas do conhecimento) e vídeos, sendo utilizado o áudio pela professora em muitas ocasiões, inclusive nas postagens dos materiais, sendo seus interlocutores os adultos, mas também as crianças. Nesses suportes textuais atividades plásticas foram propostas utilizando materiais recicláveis, assim como um convite à culinária, vídeos contendo problematizações, propostas de brincadeiras com fantoches, brincadeiras motoras, jogos simbólicos, definição de campo vocabular para o ensino dos dois idiomas (Libras e Inglês), definição de sentimentos e emoções a serem trabalhados por meio de brincadeiras, artes plásticas, oralidade, letras, escritas, etc.

Ainda que esses contos sejam narrativas, dentro de cada narrativa escolhida foram trabalhados também outros gêneros textuais, sendo eles: receitas, cartas, convites, cartões, regras de jogos, calendários, etc; sendo possível também trabalhar numerais e vogais, além do nome próprio e o conhecimento das letras a partir de seu uso social, como por exemplo, sugestões de nomes aos personagens das histórias. Também foram propostas atividades de gramática oralizada, tais como: opostos (como frio/quente), aumentativo e diminutivo (cama, caminha, camona), entre outras questões da língua.

Para fins de exemplificação dos trabalhos realizado, algumas imagens serão colocadas a fim de se pensar na Sequência Didática (SD) dos Contos Trabalhados:

Para a história da Cachinhos Dourados foram propostas as seguintes atividades:

Quadro 3: Atividades Propostas

\begin{tabular}{|c|c|c|c|c|c|}
\hline Dias & Segunda & Terça & Quarta & Quinta & Sexta \\
\hline Projetos & $\begin{array}{l}\text { Leitura, Reconto } \\
\text { e } \\
\text { Representações }\end{array}$ & Libras & $\begin{array}{ll}\text { Sentimentos } & \mathrm{e} \\
\text { Emoções } & \end{array}$ & $\begin{array}{l}\text { Artes } \\
\text { Plásticas }\end{array}$ & $\begin{array}{l}\text { Eu e Meu } \\
\text { Mundo }\end{array}$ \\
\hline SD & $\begin{array}{l}\text { Leitura em voz } \\
\text { alta por meio de } \\
\text { vídeo, utilizando } \\
\text { um vídeo pré- } \\
\text { existente }\end{array}$ & $\begin{array}{l}\text { Papai Urso } \\
\text { Mamãe } \\
\text { Ursa } \\
\text { Bebê Urso } \\
\text { Grande } \\
\text { Médio e } \\
\text { Pequeno }\end{array}$ & $\begin{array}{l}\text { Qual foi o } \\
\text { sentimento/emoção } \\
\text { da Cachinhos } \\
\text { Dourados? } \\
\text { O que ela sente } \\
\text { quando quebra a } \\
\text { cadeira do ursinho? } \\
\text { E o que o ursinho } \\
\text { sentiu ao ver o seu } \\
\text { prato vazio e sua } \\
\text { cadeira quebrada? }\end{array}$ & $\begin{array}{l}\text { Proposta de } \\
\text { realizar a } \\
\text { família urso } \\
\text { com } \\
\text { diferentes } \\
\text { materiais: } \\
\text { rolinhos de } \\
\text { papel de } \\
\text { diferentes } \\
\text { tamanhos, } \\
\text { argila, entre } \\
\text { outros. }\end{array}$ & $\begin{array}{l}\text { Proposição } \\
\text { de fazer um } \\
\text { mingau de } \\
\text { família. }\end{array}$ \\
\hline
\end{tabular}


Quadro 4: Atividades Propostas

\begin{tabular}{|l|l|l|l|l|l|}
\hline Dias & Segunda & Terça & Quarta & Quinta & Sexta \\
\hline Projetos & $\begin{array}{l}\text { Leitura (uma } \\
\text { nova versão) }\end{array}$ & Inglês & $\begin{array}{l}\text { Corpo e } \\
\text { Movimento }\end{array}$ & $\begin{array}{l}\text { Artes } \\
\text { Plásticas }\end{array}$ & $\begin{array}{l}\text { Eu e Meu } \\
\text { Mundo } \\
\text { Lives (google } \\
\text { meet) }\end{array}$ \\
\hline SD & $\begin{array}{l}\text { Leitura da } \\
\text { versão de } \\
\text { Ana Maria } \\
\text { Machado } \\
\text { Proposta de } \\
\text { dar um nome } \\
\text { a Cachinhos } \\
\text { Dourados } \\
\text { com a letra } \\
\text { inicial A }\end{array}$ & $\begin{array}{l}\text { Mesmo } \\
\text { vocabulário }\end{array}$ & $\begin{array}{l}\text { Música do } \\
\text { Grupo Triii: } \\
\text { A E I O U }\end{array}$ & $\begin{array}{l}\text { Fazer o Urso } \\
\text { e passar o } \\
\text { barbante nos } \\
\text { buracos } \\
\text { feitos. }\end{array}$ & $\begin{array}{l}\text { Reunião com } \\
\text { as crianças: }\end{array}$ \\
& & & $\begin{array}{l}\text { Falamos } \\
\text { sobre a } \\
\text { atitude da } \\
\text { Cachinhos } \\
\text { Dourados, } \\
\text { demos } \\
\text { exemplos de } \\
\text { que não } \\
\text { podemos } \\
\text { pegar nada } \\
\text { sem pedir } \\
\text { emprestado. }\end{array}$ \\
& & & & \\
& & & \\
& & & \\
& & & \\
\end{tabular}

Essas atividades foram pensadas em conjunto com as professoras das distintas áreas do conhecimento e que por meio da parceria tem nos orientado a partir das suas especificidades, sendo elas: Terapia Ocupacional, Educação Física, Educação Especial, Psicologia, Letras e Linguística. Em consonância com a teoria histórico-cultural, a proposição de situações de brincadeiras permite que as crianças utilizem seus conhecimentos de mundo a fim de aprender alguns conhecimentos científicos que Ihes são ensinados. Algumas ilustrações relativas aos trabalhos realizados:

\begin{tabular}{|c|c|c|}
\hline $\begin{array}{l}\text { Criança 1: Pintura } \\
\text { com Guache no } \\
\text { Papelão. Escolha do } \\
\text { nome para a } \\
\text { personagem: Alice }\end{array}$ & $\begin{array}{l}\text { Criança 2: Jogo de } \\
\text { casa e fez a letra A. } \\
\text { Nome escolhido para a } \\
\text { personagem: Ana }\end{array}$ & $\begin{array}{l}\text { Criança 3: Letra A feita } \\
\text { no papel sulfite e pintura } \\
\text { com cola e purpurina. } \\
\text { Nome escolhido: Alícia }\end{array}$ \\
\hline
\end{tabular}




\section{STUD|原S}

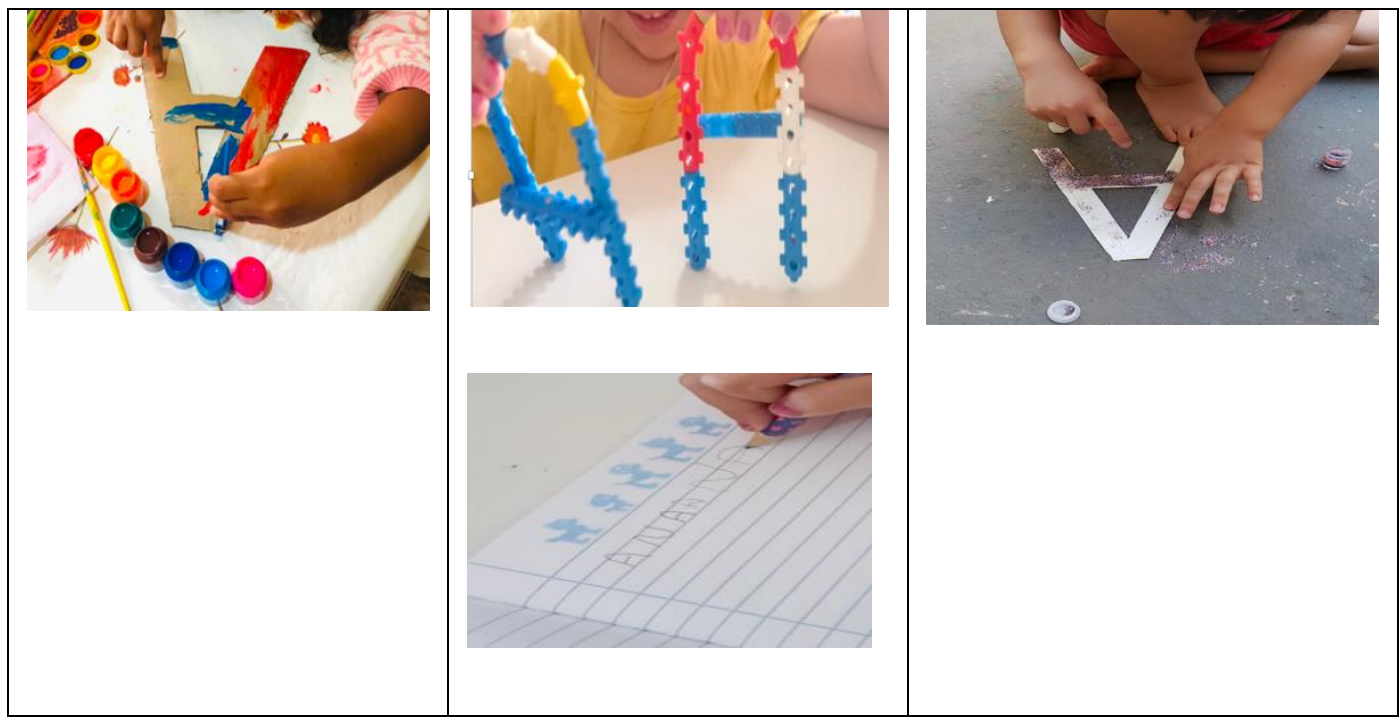

Imagem 1: Crianças ilustrando a letra $\mathrm{A}$ inicial escolhida para um nome à Cachinhos Dourados



Imagem 2: Crianças brincando com a família urso e seus diferentes tamanhos

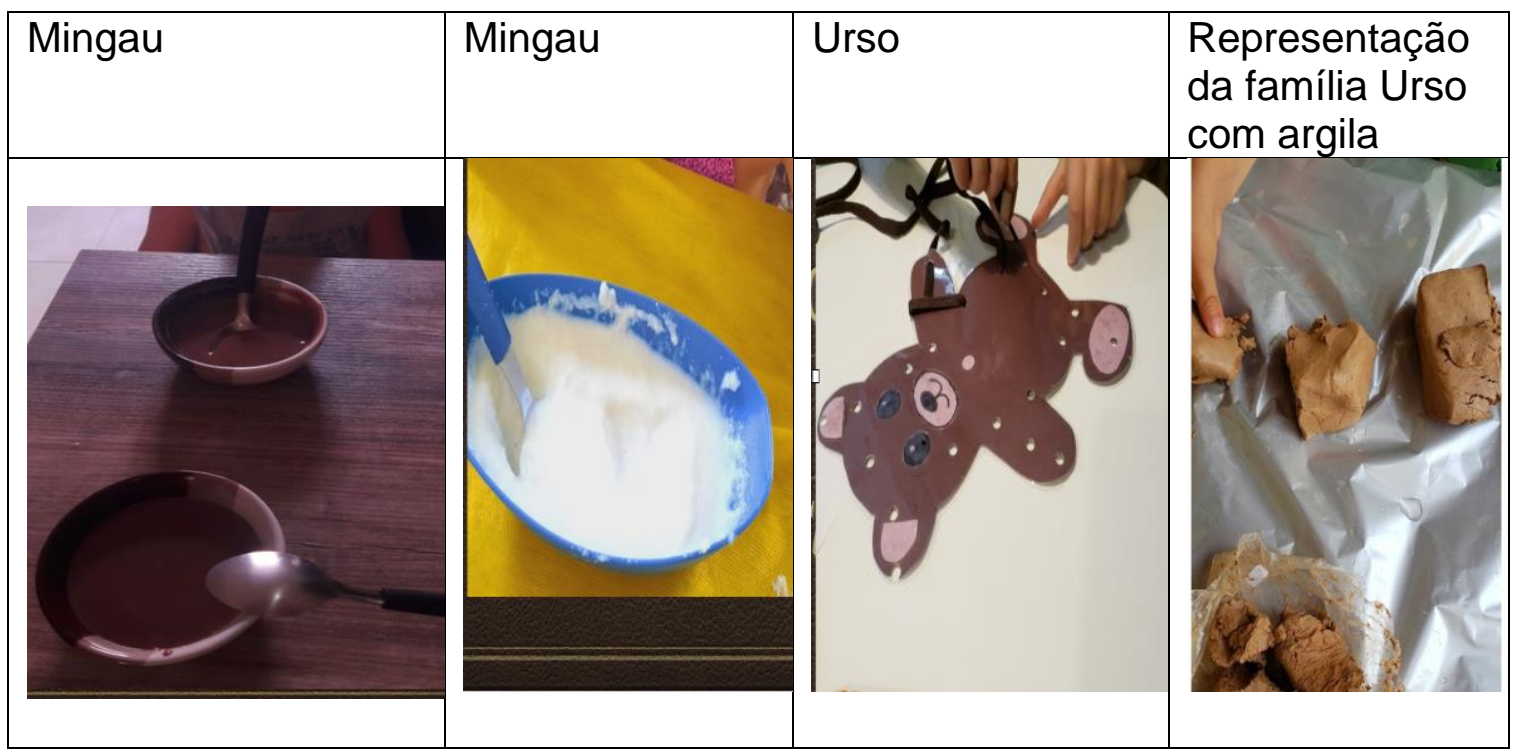


Imagem 3: Crianças realizaram o Mingau e atividades motoras

Imagem 4: Música do Grupo Trii e Yoga das Vogais na Live

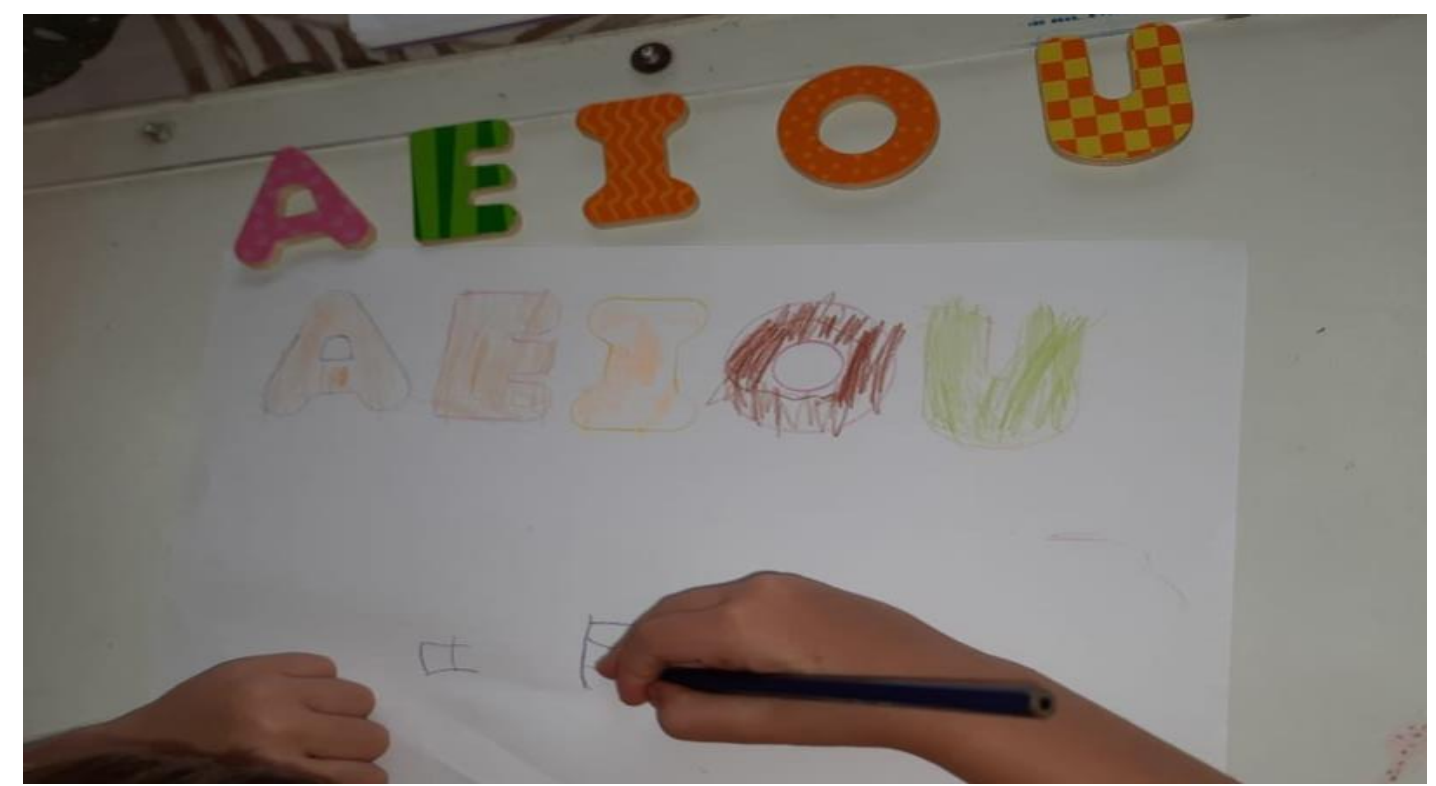

Não cabe neste artigo demonstrar as sequências didáticas de cada trabalho desenvolvido a partir dos Contos de Fadas, todavia é necessário afirmar que é possível trabalhar as diferentes linguagens das crianças a partir deles. Para tanto, algumas fotografias serão inseridas de forma ilustrativa dos trabalhos realizados com o conto "João e o pé-de-feijão". Vejamos:

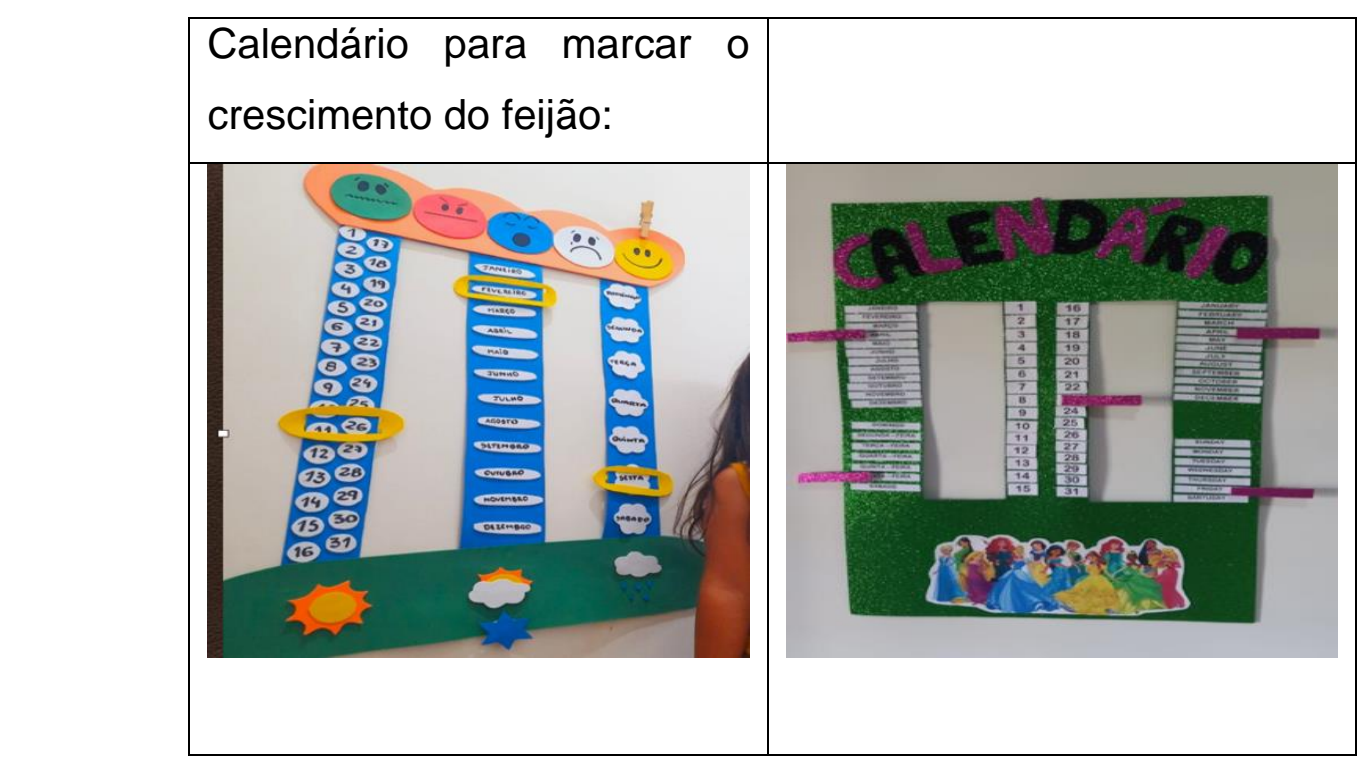

Imagem 5: Calendários 
Uso do Feijão para plantar, cozinhar e ainda colocar a quantidade para a representação numérica.
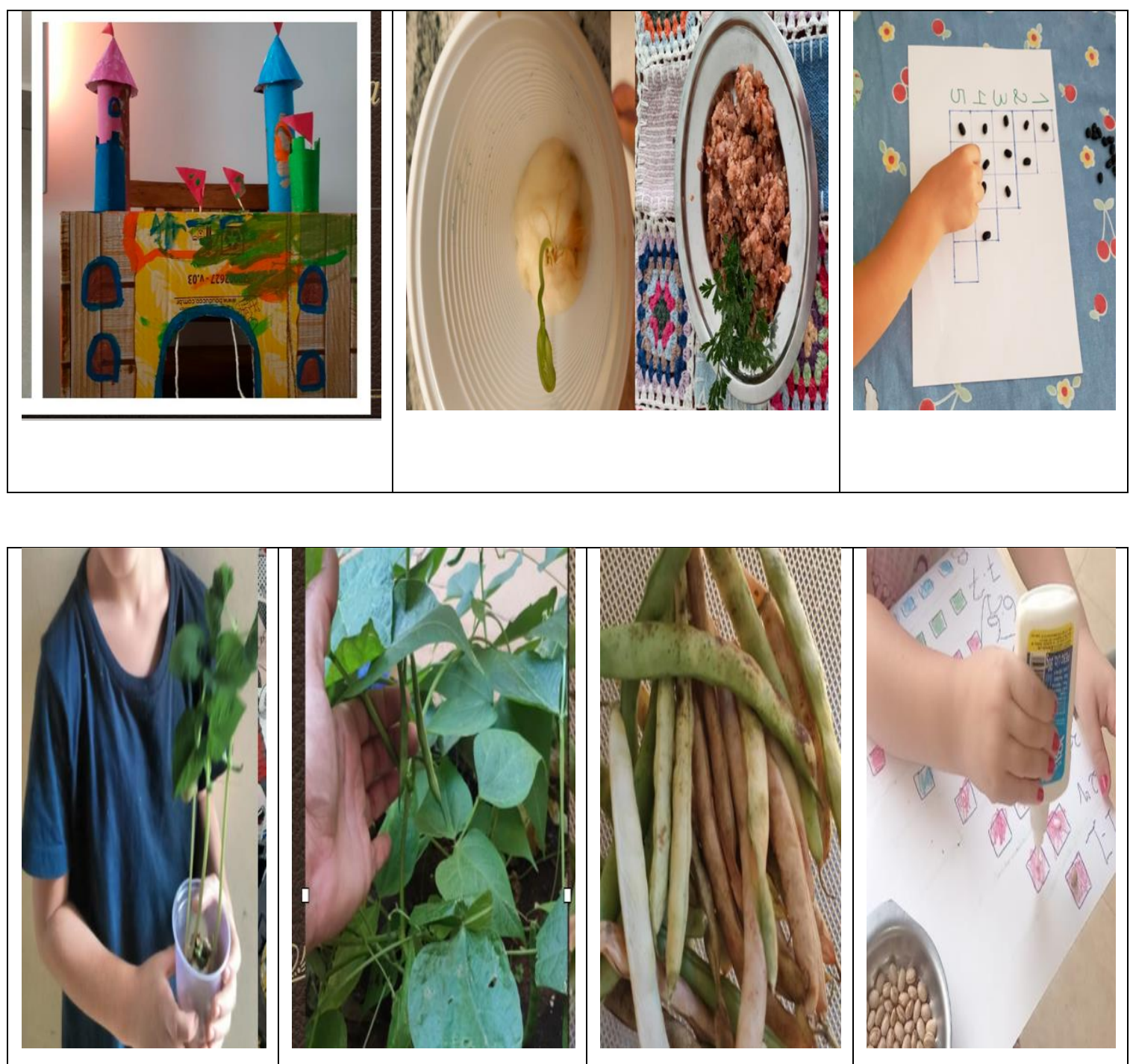

Imagem 6: llustração dos trabalhos e produções a partir das histórias

De acordo com a teoria Histórico-Cultural, tendo Vygotsky (2001) como o precursor desta teoria, a categoria de mediação visa constituir uma ponte por meio de signos e símbolos e também objetos para que seja possível estabelecer um processo de aprendizado mediado por aquele que nos ensina intencionalmente, como é o caso da docência. Podemos ouvir a história da "Cachinhos Dourados e os três ursos", podemos nos deleitar com a história, mas também podemos problematizar e trabalharmos diferentes frentes do conhecimento e das distintas linguagens que as crianças possuem. Loris Malaguzzi (2019) anunciava que as crianças possuem cem linguagens diferentes e que as escolas acabam, muitas vezes podando noventa e nove. 
Diante desse ponto de vista, promover um ensino intencional explorando esta diversidade de linguagens, como as atividades propiciadas pela Terapia Ocupacional que permite o desenvolvimento cognitivo, emocional, motor, que possibilita à criança não somente a autonomia nas suas atividades de vida diárias (AVDs), mas que também promove habilidades que a ajudarão nas atividades de escrita futura. Permitir que elas possam nomear as emoções, sentir as emoções dos personagens das histórias, possibilita que elas pouco a pouco compreendam aquilo que sentem e passem a nomear, evitando birras, brigas, entre outros gestos típicos do ser que está em construção e que ainda não sabe expressar-se por meio da linguagem oral.

Portanto, utilizar a arte, o desenho, o teatro, permite ainda que essas crianças explorem tais atividades, desde a emoção, o jogo simbólico, o seu desenvolvimento motor, entre outros. Conforme tão bem salientou Libâneo (2013), quanto mais oportunidades de expressão da sua subjetividade, mais significativo a aprendizagem e mais chances a criança terá de entender seu mundo emocional sobre o mundo concreto. A arte, de acordo com o autor, é o caminho capaz de promover essas oportunidades de experimentação e aprendizagem.

Se colocar no lugar do outro com o exercício de questões problematizadoras, permite que a criança passe a compreender o seu eu-social, cujas regras de convívio inclui aceitar e respeitar as diferenças. Ensinar dois idiomas distintos nesta tenra idade também permite à criança experimentar participar do processo de inclusão, sendo a língua inglesa um idioma tido como universal, já o idioma Libras, por outro lado, se constitui a língua de um pequeno grupo excluído socialmente. É nesse paradoxo dos direitos à inclusão, que pensamos o ensino de diferentes línguas as crianças.

\section{CONSIDERAÇÕES FINAIS}

Diante do exposto, nestas poucas linhas quisemos abordar um ensino colaborativo e em parceria com diferentes áreas do saber e, principalmente, uma parceria com as famílias em prol das crianças pequenas. Apesar de olharmos para esse processo de ensino e aprendizado, não pudemos acompanhar o desenvolvimento de nossas crianças, tal como ocorria na sala de aula, uma vez que foram os familiares que dividiram com os pequenos este processo. O que 
recebemos foram fotografias, vídeos e áudios, assim como enviávamos a eles esses registros das atividades realizadas no ambiente escolar. Por meio desta documentação pedagógica compartilhada amorosamente pelas famílias como feedback das sugestões de atividades propostas também de forma amorosa, pudemos ter pequenos momentos de alegria durante esse ensino remoto.

Pensar o processo formativo das crianças, mas também daqueles que estão em sua formação inicial, contribuir com a formação de jovens pesquisadores e extensionistas, bem como com a de futuros professores, permite exercermos aquilo que se pressupõe da Universidade e de uma escola pública de qualidade "ensino, pesquisa e extensão" em diálogo no fazer pedagógico da sala de aula, cuja teoria alimenta a prática diária e essa alimenta as perguntas e indagações para que novas teorias sejam tecidas a partir de uma construção conjunta entre os saberes da experiência e os saberes científicos. Afinal o cotejo das vozes contidas na literatura infantil constitui-se como um caminho metodológico para compreender o mundo a nossa volta. Propiciar a leitura de mundo às nossas crianças a partir da leitura das palavras contidas nas histórias infantis é fornecer a elas subsídios para desvendar e criar novos mundos. 


\section{REFERÊNCIAS}

Abramovich, fanny. Literatura infantil: gostosuras e bobices. 5 ed. São paulo: Scipione, 2001.

Bakhtin, mikhail. Marxismo e filosofia da linguagem. Editora hucitec, 14 ed., 2010. Bakhtin, mikhail. Estética da criação verbal. Martins fontes, 4 ed., 2003.

Brasil. Ministério da educação. Base nacional comum curricular. Brasília, 2018. Freire, paulo. Pedagogia da autonomia: saberes necessários à prática educativa. 31 ed. São paulo: paz e terra, 1996.

Freire, paulo. Alfabetização: leitura do mundo leitura da palavra, paz e terra, 4 ed.2006.

Libânio, a, m, s. Educação pela arte: uma experiência para dar sentido aos sentidos. 2013. 213 f. Mestrado (mestre em educação) - faculdade de ciências sociais e humanas - universidade nova de lisboa, [s. L.], 2013. Disponível em: https://run.unl.pt/bitstream/10362/10826/1/capa\%20interior\%20\%28cd\%29.pdf. Acesso em: 20/021/21.

Lüdke, m.; andré, m.e.d.a. Pesquisa em educação: abordagens qualitativas. São paulo: epu/edusp, 1986.

Vygotsky, liev.; luria, alexander; leontiev, alex. Linguagem, desenvolvimento e aprendizagem. 7. Ed. Icone editora, 2001.

Vygotsky, liev. S. A construção do pensamento e da linguagem. Martins fontes, 2001. 